\title{
Coastal eutrophication research: a new awareness
}

\author{
Carlos M. Duarte
}

Published online: 10 May 2009

(C) Springer Science+Business Media B.V. 2009

\begin{abstract}
An analysis of the contents and conclusions of the papers contained in this issue (Hydrobiologia Volume $\mathrm{xxx}$ ) suggests that a new vision is taking shape that may correspond to an emerging new paradigm in the way we understand and manage coastal eutrophication. This new paradigm emphasizes its global dimension and the connections with other global environmental pressures, and re-evaluates the targets of remedial actions and policies. Eutrophication research must evolve toward a more integrative, ecosystem perspective which requires that it be extended to include impacts beyond primary producers and to examine possible cascading effects and feedbacks involving other components of the ecosystem. A quantitative framework that incorporates the interacting top-down and bottom-up effects in eutrophication models must be urgently developed to guide
\end{abstract}

Guest editors: J. H. Andersen \& D. J. Conley

Eutrophication in Coastal Ecosystems: Selected papers from the Second International Symposium on Research and Management of Eutrophication in Coastal Ecosystems, 20-23 June 2006, Nyborg, Denmark

C. M. Duarte $(\square)$

IMEDEA (CSIC-UIB), Miquel Marqués 21,

07190 Esporles, Spain

e-mail: carlosduarte@ifisc.uib.es diagnostics and establish targets to mitigate coastal eutrophication. The required macroscopic view must also be extended to the managerial and policy frameworks addressing eutrophication, through the development of policies that examine activities in the environment in an integrative, rather than sectorial, manner. Recent evidence of complex responses of coastal ecosystems to nutrient reduction requires that management targets, and the policies that support them, be reconsidered to recognize the complexities of the responses of coastal ecosystems to reduced nutrient inputs, including non-linear responses and associated thresholds. While a predictive framework for the complex trajectories of coastal ecosystems subject to changes in nutrient inputs is being developed, the assessment of managerial actions should be reconsidered to focus on the consideration of the status achieved as the outcome of nutrient reduction plans against that possibly derived from a 'do nothing' scenario. A proper assessment of eutrophication and the efforts to mitigate it also requires that eutrophication be considered as a component of global change, in addressing both its causes and its consequences, and that the feedbacks between other components of global change (e.g., climate change, overfishing, altered biogeochemical cycles, etc.) be explicitly considered in designing eutrophication research and in managing the problem.

Keywords Eutrophication - Oligotrophication · Global change · Nutrient · Coastal ecosystems · Management targets 


\section{Introduction}

About 15 years have elapsed between the first conference on coastal eutrophication convened in Denmark, in 1993, and the Second International Symposium on Research and Management of Eutrophication in Coastal Ecosystems (Nyborg, Denmark, 20-23 June, 2006), the results of which are collected in this special issue. The symposium addressed a range of topics (Andersen \& Conley, 2009) and promoted active discussion among the 200 participants. Whereas the first conference included the definition of 'eutrophication' as a noun (Nixon, 1995), the definition now coined by Scott Nixon is that for 'oligotrophication,' the antonym of eutrophication (Nixon, 2009). This is symptomatic of the evolution of eutrophication science and the management of eutrophied coastal ecosystems.

In 1993, we were creating an awareness of the spread of eutrophication as a threat to coastal ecosystems, lagging about two decades behind the recognized impacts of eutrophication in lakes. We now have a better appreciation of the scale of problem (e.g., Nixon, 2009), a better understanding of its processes and dynamics (e.g., Cloern, 2001; Boesch, 2002; Howarth \& Marino, 2006; Conley et al., 2009; Duarte et al., 2009; Soetaert \& Middelburg, 2009), improved diagnostic tools and indicators (e.g., Eyre \& Ferguson, 2009; Jaanus et al., 2009), and have taken action to mitigate it (e.g., Nørring \& Jørgensen, 2009, Petersen et al., 2009; Savchuk \& Wulff, 2009), as clearly exemplified by the papers compiled in this issue. Collectively, these papers portray a major development of the field over the past decade. Although less explicitly, a critical analysis of the contents and conclusions of these papers, along with recent papers published elsewhere, suggests that a new vision is taking shape that may correspond to an emerging new paradigm in the way we understand and manage coastal eutrophication.

In this summary, I will not attempt to list the insights derived from each individual contribution to this special issue, which can best be obtained through an examination of the papers themselves. I will, instead, focus on what these papers collectively inform as the challenge for coastal eutrophication research in the future. I argue that these challenges accrete to conform a new vision of coastal eutrophication that emphasizes its global dimension and connection with other global environmental pressures, and reconsiders the targets for remedial actions and policies.

\section{Challenges for coastal eutrophication research}

Eutrophication research has focused mainly on phytoplankton, but clearly eutrophication impacts on all components of coastal ecosystems. The diagnostics of these impacts require that robust indicators be developed that help assess the responses of coastal ecosystems to eutrophication (e.g., Jaanus et al., 2009). The search for reliable ecosystem-level indicators of eutrophication impacts is not driven by an academic interest in better understanding eutrophication, but by the requirements of legislation and policy to identify and abate coastal eutrophication, as exemplified by the EU Water Framework Directive and the OSPAR Convention (e.g., Claussen et al., 2009; Duarte et al., 2009; Henriksen, 2009). Long-lived components of coastal ecosystems sensitive to degraded water quality, such as seagrass, can be particularly useful because their response integrates variability in nutrient concentrations and water quality, offering a robust diagnostic of change (Duarte, 1995, 2002; Olivé et al., 2009). Such an ecosystem approach to understanding and managing eutrophication requires that research be extended to include impacts beyond primary producers and to examine possible cascading effects and feedbacks involving other components of the ecosystem.

The role of changes in the upper levels of the food web in facilitating eutrophication has received limited attention, but research on eutrophied coral reef ecosystems has clearly shown that the integrity of the fish community can greatly affect the resilience and resistance of coral reefs to eutrophication (Dulvy et al., 2004; Mumby et al., 2006). Indeed, a recent metaanalysis of the role of fish removal in the loss of ecosystem resistance to eutrophication has provided compelling evidence that the depletion of top predators from coastal waters may have increased the vulnerability of coastal ecosystems to eutrophication (Heck \& Valentine, 2007). Heck \& Valentine (2007) showed that the widespread overharvesting of large consumers, which once played pivotal roles in regulating ecosystem structure and function (Jackson et al., 2001), may trigger indirect effects that may enhance those of eutrophication. Indeed, overfishing and eutrophication 
have strong interactive effects. Breitburg et al. (2009) argue that nutrient enrichment and habitat degradation causes reduced yields of fisheries, whereas fisheries exploitation can affect the ability of estuarine systems to process nutrients, enhancing eutrophication symptoms. Whereas general relationships between nutrient inputs and concentrations, and chlorophyll $a$ concentrations are available (e.g., Smith, 2006), there is no predictive framework that integrates the interactive top-down and bottom-up forces in the development of eutrophication symptoms. A quantitative framework that incorporates the interacting top-down and bottomup effects in eutrophication models must be urgently developed to guide diagnostics and establish targets to mitigate coastal eutrophication.

The development of a broader ecosystem approach to coastal eutrophication often stumbles on the difficulties of defining the extent of coastal ecosystems. Coastal ecosystems have clearly defined, objective boundaries inland but their offshore extent is generally unclear, and its delineation remains critical to properly manage eutrophication problems (Kratzer \& Tett, 2009; Lessin et al., 2009). Moreover, whereas most approaches focus on land-derived influences (i.e., nutrient inputs) on eutrophication dynamics, forcing derived from interactions with the adjacent offshore waters may determine significant departures from the expected dynamics (e.g., Cloern et al., 2007; Savchuk et al., 2009). This requires that forcing by both inland (human-dominated) and offshore (climate-dominated) processes be considered in predicting and understanding eutrophication dynamics in the coastal zone. For example, long-term analysis of Narragansett Bay provided evidence of climate-induced oligotrophication in the absence of any significant reduction in nutrient concentrations or inputs (Fulweiler \& Nixon, 2009).

The above plea for a more integrative ecosystem approach to eutrophication research may be interpreted to reinforce the tradition to study and manage eutrophication at the individual ecosystem level. However, it is becoming increasingly evident that eutrophication must be examined in a much broader context. Nixon (2009) makes a strong case, drawing on advice he received from his mentor, the late $\mathrm{H}$. T. Odum, to examine eutrophication issues at a scale larger than the individual ecosystem, applying a macroscope to better capture the dimensions and controls of the forces that shape eutrophication problems. This case can be forcefully made by considering the problems of eutrophication-driven hypoxia in the Gulf of Mexico, the causes and dynamics of which have been traced back to agricultural practices in the Corn Belt, thousands of kilometers away from the coastal region where the problem is manifested (Burkart \& James, 1999). Moreover, the application of such a macroscope does not need to be restricted to understand the environmental processes, excess nutrient use and export that our concept of eutrophication identifies as the cause of the problem, but it may also incorporate the underlying social dynamics. For example, it has recently been argued that the rapid growth of biofuel crops in the Corn Belt affects the prospect for decreasing the hypoxic area in the Gulf of Mexico, as it is likely to lead to increased fertilizer application in the Corn Belt (Hill et al., 2006).

Indeed, agricultural, fisheries, water quality and even energy policies all affect coastal eutrophication, even though these policies do not recognize such connections and are often issued as if they bore no relationship to the eutrophication problem. Recognizing that excess fertilizer and manure application to agricultural soils is a main driver of coastal eutrophication, many nations have invested important resources to reduce nitrogen effluents. These efforts are currently championed by Denmark, which implemented a number of different Action Plans against water pollution focused on the agricultural sector that have successfully led to a reduction in the total loss of nitrogen from farmland by approximately $50 \%$ compared to the mid-1980s (Nørring \& Jørgensen, 2009). While the analysis of nitrogen inputs to coastal waters has focused on activities on land, the importance of the fisheries sector in removing nutrients from coastal ecosystems has only recently been identified. Indeed, Maranger et al. (2008) recently reported that fisheries mobilize almost as much nitrogen, bound in the N-rich tissues of marine organisms, from the oceans back to land as that delivered from land to the oceans. The large amount of nitrogen removed with the harvesting of marine animals has led Lindahl \& Kollberg (2009) to propose that mussel farming, which has been recognized by Swedish environmental authorities as a possible measure to improve coastal water quality, be subsidized by sectors that emit nutrients, such as agriculture, through the trading of emission quotas. Specifically, Lindahl \& Kollberg (2009) argue that 
because most of the nutrient supply to coastal waters in many areas of Europe derives from agricultural operations, funding from the EU agro-environmental program should subsidize mussel farming enterprises in the same way that agricultural farmers are supported to reduce nutrient leakage from their farmlands. Again, this requires the development of policies that examine activities in the environment in an integrative, rather than sectorial, manner.

Most importantly, recent evidence of complex responses of coastal ecosystems to nutrient reduction requires that management targets, and the policies that support them, be reconsidered. An examination of the responses of coastal ecosystems to reduced nutrient inputs shows that these responses often deviate from the simple decline in chlorophyll $a$ concentrations that is expected based on the underlying assumption of a direct relationship between nutrient inputs and eutrophication symptoms (Kemp et al., 2005; Duarte et al., 2009). Failure to observe the expected improvements in response to the reductions in nutrient inputs can be very frustrating for the public and managers and can undermine their willingness to undertake future reductions; this must be urgently addressed (Duarte et al., 2009). For instance, in Denmark, arguably the country that has led efforts to reduce nutrient inputs, the $43 \%$ reduction in the nitrogen load to the marine environment in the period 1989-2003 has resulted in only minor improvements at the ecosystem level, generating the perception of a disproportion between the cost of nutrient reduction plans and the improvements achieved (Nørring \& Jørgensen, 2009). Indeed, whereas increased nutrient inputs have clearly led to increased coastal eutrophication, the reverse, oligotrophication (i.e., a reduced production of organic matter; Nixon, 2009), does not appear to be a necessary, nor prevalent, outcome of reduced nutrient inputs.

We have long understood the complexity of factors involved in the eutrophication process (Cloern, 2001; Kemp et al., 2005) but, these complexities have not been adequately conveyed to managers and legislators, who have received a simplified view of a direct control of chlorophyll $a$ concentration, as a metric of water quality, by nutrient inputs (Duarte et al., 2009). A new paradigm is emerging that recognizes the complexities of the factors and dynamics involved in the response of coastal ecosystems to reduced nutrient inputs (e.g., Conley et al., 2009; Duarte et al., 2009).
Only now, three decades after eutrophication problems were realized as a major problem affecting coastal ecosystems are data becoming available to show the trajectories of ecosystems following increased and subsequently reduced nutrient inputs (Duarte et al., 2009). Examination of these trajectories reveals that the response of coastal ecosystems to reduced nutrient inputs appears to display complex, non-linear dynamics. A first driver of such non-linearities is the occurrence of thresholds of nutrient inputs beyond which abrupt changes in the response of the ecosystem occur (e.g., Duarte et al., 2009). Such threshold responses have been identified and analyzed in the case of the decline in oxygen in response to increased nutrient concentrations (Conley et al., 2009), whereby the occurrence of hypoxia creates a number of buffers (loss of benthic organisms, build up of sulfides, and others) that render ecosystems who have experienced hypoxia more prone to experience subsequent hypoxia even if nutrient concentrations are reduced (Conley et al., 2009). A second factor is the occurrence of time lags in the responses owing to the accumulation and release of nutrients in the sediments (Soetaert and Middelburg, 2009) or the long time spans involved in the recovery of some inherently slow-growing organisms, such as seagrass (Duarte, 1995). These time lags result in apparent hysteresis in response to nutrient reductions that appear as non-linearities in the trajectories of ecosystem status during increased and reduced nutrient concentrations (Duarte et al., 2009). Finally, non-linearities may derive from shifting baselines altering the relationship between chlorophyll $a$ and nutrient inputs over time (Duarte et al., 2009). The trajectories of coastal ecosystems from the onset of eutrophication to the achievement of nutrient reductions occur typically over two to three decades, sufficiently long for other relevant forcing factors, including top predators in the system, climate, hydrology, land use in the catchment, atmospheric carbon dioxide $\left(\mathrm{CO}_{2}\right)$ concentrations, etc., to have changed significantly (Duarte et al., 2009), possibly affecting the yield of chlorophyll, or the extent of eutrophication, per unit nutrient in the system. Shifting baselines along the eutrophication-to-oligotrophication transition may result in an apparent failure to achieve the extent of reduction in chlorophyll $a$ concentration sought by nutrient reduction programs.

The awareness of the importance of abrupt changes in coastal ecosystems as nutrient inputs 
increase beyond critical tipping points is largely a consequence of the increasing availability of time series data extending over three decades to encompass the eutrophication and oligotrophication periods. Indeed, the availability of these time series occurs at a time when new statistical techniques have become available to search for and detect abrupt changes and thresholds (Andersen et al., 2008), providing an opportunity to learn more about the non-linearities affecting the relationship between chlorophyll $a$ concentration and changes in nutrient inputs in coastal ecosystems.

While we struggle to understand and develop a predictive framework for the complex trajectories of coastal ecosystems from eutrophication to subsequent oligotrophication, it is imperative that we reassess our advice to managers and, particularly, the targets of nutrient reduction plans. Focusing on the improvements, although unavoidable, can be discouraging. The expectation that coastal ecosystems will return to an original status prior to significant eutrophication, following nutrient reduction efforts has recently been criticized as naïve, because it implies the return to a past situation that may be precluded by major concurrent changes in the global environment, the shifting baselines (Duarte et al., 2009). Hence, a better framework for action may involve consideration of the status achieved as the outcome of nutrient reduction plans against that possibly existing under a 'do nothing' scenario, which may include acceptable deviations from the status prior to eutrophication. Indeed, this is the approach adopted for other environmental problems, such as climate change, where the ambition is to stop further warming of the planet, thereby avoiding the associated impacts, rather than cooling the planet back to the preindustrial climate. The alternative approach proposed here is, however, precluded by the lack of appropriate frameworks to assess what would have been the trajectories of ecosystems if nutrient inputs had not been reduced, which is the correct, albeit elusive, context in which the outcome of efforts to reduce nutrient inputs should be assessed. The development of such predictive frameworks should have a high priority in the future of eutrophication research. Moreover, the resistance of eutrophied and hypoxic ecosystems to become more oligotrophic upon reductions in nutrient inputs (Conley et al., 2009; Duarte et al., 2009) should alert managers and policy- makers to the importance of preventing eutrophication because the costs of mitigating eutrophication may be far higher than those of avoidance measures.

\section{Coastal eutrophication as a component of global change}

Once again, we find ourselves in need of the macroscopic view when evaluating the research challenges. Effective management requires that we integrate policies across sectors within and beyond the domains of the coastal ecosystems and that we move away from oversimplified views on the controls of eutrophication to consider the operation of factors beyond nutrient inputs, including overfishing, the occurrence of invasive species and climate change, among others. Most important, a look through the global macroscope readily reveals that coastal eutrophication is not a process affecting individual ecosystems, but is a global phenomenon both in its global spread and in the relative synchrony of this spread. The forces that shape coastal eutrophication include human population growth, changes in land use, massive production of $\mathrm{N}$ in fertilizers through the Haber reaction, increased anthropogenic emissions of reactive nitrogen species to the atmosphere, increased atmospheric $\mathrm{CO}_{2}$, climate change and overfishing (Duarte et al., 2009; Nixon, 2009), all recognized as forces affecting global change.

Moreover, it may be argued that coastal eutrophication may have the potential to impact the function of the Earth System at the regional and, possibly, global level through changes affecting the trophic dynamics and biogeochemical cycling of the coastal ocean. For example, the increase in hypoxia is clearly a global phenomenon affected by global warming, but also by widespread eutrophication of coastal ecosystems (Díaz \& Rosenberg, 2008; VaquerSunyer \& Duarte, 2008; Conley et al., 2009). Hence, eutrophication should be considered as a component of global change, in addressing both its causes and its consequences (Duarte et al., 2009), and as such incorporated into major international collaborative programs to address global change. Seeing eutrophication in the macroscopic view of global change is important to better understand and manage the phenomenon (Duarte et al., 2009; Nixon, 2009).

In conclusion, whereas our understanding of coastal eutrophication has progressed in parallel with efforts to 
reduce nutrient inputs to coastal ecosystems, major challenges are still ahead of us in the development of a refined understanding that allows prediction of the dynamics of coastal ecosystems subject to simultaneous changes in nutrient inputs and other global forcing factors that lead to a continuous shift in baselines. Most importantly, we must urgently resume a dialog with managers and legislators that more humbly acknowledges the complexities of the problem and the limitations of our capacity to predict the trajectories of managed coastal ecosystems. We must develop a new vision of the effectiveness of efforts to mitigate eutrophication that focuses not only on the changes relative to the initial conditions, but also on the benefits relative to a 'do nothing' policy. Realization of the difficulties of reversing eutrophication, owing to the multiple mechanism that lead to a resistance of coastal ecosystems to reverse the eutrophied state once entered, must also reinforce policies and efforts to avoid eutrophication, the costs of which are likely to be far lower than those of remedial actions.

Acknowledgements This is a contribution to the THRESHOLDS and WISER project, funded by the FP6 and FP7 programs of the EU (contracts \# 003933-2 and 226273, respectively). I thank the guest editors of this issue (Jesper H. Andersen and Daniel J. Conley) for the invitation to the conference and to contribute this article.

\section{References}

Andersen, J. H. \& D. J. Conley, 2009. Eutrophication in coastal marine ecosystems: Towards better understanding and management strategies. Hydrobiologia (this issue). doi: 10.1007/s10750-009-9758-0.

Andersen, T., J. Carstensen, E. Hernández-García \& C. M. Duarte, 2008. Ecological thresholds and regime shifts: approaches to identification. Trends in Ecology and the Environment 24: 49-57.

Boesch, D. F., 2002. Challenges and opportunities for science in reducing nutrient over-enrichment of coastal ecosystems. Estuaries 25: 886-900.

Breitburg, D. L., J. K. Craig, R. S. Fulford, K. A. Rose, W. R. Boynton, D. C. Brady, B. J. Ciotti, R. J. Diaz, K. D. Friedland, J. D. Hagy III, D. R. Hart, A. H. Hines, E. D. Houde, S. E. Kolesar, S. W. Nixon, J. A. Rice, D. H. Secor \& T. E. Targett, 2009. Nutrient enrichment and fisheries exploitation: interactive effects on estuarine living resources and their management. Hydrobiologia (this issue). doi:10.1007/s10750-009-9762-4.

Burkart, M. R. \& D. E. James, 1999. Agricultural-nitrogen contributions to hypoxia in the Gulf of Mexico. Journal of Environmental Quality 28: 850-859.
Claussen, U., W. Zevenboom, U. Brockmann, D. Topcu \& P. Bot, 2009. Assessment of the eutrophication status of transitional, coastal and marine waters within the OSPAR. Hydrobiologia (this issue). doi:10.1007/s10750-009-9763-3.

Cloern, J., 2001. Our evolving conceptual model of the coastal eutrophication problem. Marine Ecology Progress Series 210: 223-253.

Cloern, J. E., A. D. Jassby, J. K. Thompson \& K. A. Hieb, 2007. A cold phase of the East Pacific triggers new phytoplankton blooms in San Francisco Bay. Proceedings of the National Academy of Sciences 104: 18561-18565.

Conley, D. J., J. Carstensen, R. Vaquer-Sunyer \& C. M. Duarte, 2009. Ecosystem thresholds with hypoxia. Hydrobiologia (this issue). doi:10.1007/s10750-009-9764-2.

Díaz, R. J. \& R. Rosenberg, 2008. Spreading dead zones and consequences for marine ecosystems. Science 321: 926-929.

Duarte, C. M., 1995. Submerged aquatic vegetation in relation to different nutrient regimes. Ophelia 41: 87-112.

Duarte, C. M., 2002. The future of seagrass meadows. Environmental Conservation 29: 192-206.

Duarte, C. M., D. J. Conley, J. Carstensen \& M. SánchezCamacho, 2009. Return to Neverland: shifting baselines affect eutrophication restoration targets. Estuaries and Coasts 32: 29-36.

Dulvy, N. K., R. P. Freckleton \& N. V. C. Polunin, 2004. Coral reef cascades and the indirect effects of predator removal by exploitation. Ecology Letters 7: 410-416.

Eyre, B. D. \& A. J. P. Ferguson, 2009. Denitrification efficiency for defining critical loads of carbon in shallow coastal ecosystems. Hydrobiologia (this issue). doi:10.1007/s10750009-9765-1.

Fulweiler, R. W. \& S. W. Nixon, 2009. Responses of benthicpelagic coupling to climate change in a temperate estuary. Hydrobiologia (this issue). doi:10.1007/s10750-0099766-0.

Heck, K. L. Jr. \& J. F. Valentine, 2007. The primacy of topdown effects in shallow benthic ecosystems. Estuaries and Coasts 30: 371-381.

Henriksen, P., 2009. Reference conditions for phytoplankton at Danish Water Framework Directive intercalibration sites. Hydrobiologia (this issue). doi:10.1007/s10750-009-9767-z.

Hill, H., E. Nelson, D. Tilman, S. Polasky \& D. Tiffany, 2006. Environmental, economic, and energetic costs and benefits of biodiesel and ethanol biofuels. Proceedings of the National Academy of Sciences of the United States of America 103: 11206-11210.

Howarth, R. W. \& R. Marino, 2006. Nitrogen as the limiting nutrient for eutrophication in coastal marine ecosystems: evolving views over 3 decades. Limnology and Oceanography 51: 364-376.

Jaanus, A., K. Toming, S. Hällfors, K. Kaljurand \& I. Lips, 2009. Potential phytoplankton indicator species for monitoring Baltic coastal waters in the summer period. Hydrobiologia (this issue). doi:10.1007/s10750-009-9768-y.

Jackson, J. B. C., M. X. Kirby, W. H. Berger, et al., 2001. Historical overfishing and the recent collapse of coastal ecosystems. Science 293: 629-638.

Kemp, W. M., W. R. Boynton, J. E. Adof, et al., 2005. Eutrophication of Chesapeake Bay: historical trends and ecological interactions. Marine Ecology Progress Series 303: 1-29. 
Kratzer, S. \& P. Tett, 2009. Using bio-optics to investigate the extent of coastal waters: a Swedish case study. Hydrobiologia (this issue). doi:10.1007/s10750-009-9769-x.

Lessin, G., V. Ossipova, I. Lips \& U. Raudsepp, 2009. Identification of the coastal zone of the central and eastern Gulf of Finland by numerical modeling, measurements, and remote sensing of chlorophyll $a$. Hydrobiologia (this issue). doi:10.1007/s10750-009-9770-4.

Lindahl, O. \& S. Kollberg, 2009. Can the EU agro-environmental aid program be extended into the coastal zone to combat eutrophication? Hydrobiologia (this issue). doi: 10.1007/s10750-009-9771-3.

Maranger, R., N. Caraco, J. Duhamel \& M. Amyot, 2008. Nitrogen transfer from sea to land via commercial fisheries. Nature Geosciences 1: 111-113.

Mumby, P. J., C. P. Dahlgren, A. R. Harborne, C. V. Kappel, F. Micheli, D. R. Brumbaugh, K. E. Holmes, J. M. Mendes, K. Broad, J. N. Sanchirico, K. Buch, S. Box, R. W. Stoeffle \& A. B. Gill, 2006. Fishing, trophic cascades, and the process of grazing on coral reefs. Science 311: 98-101.

Nixon, S. W., 1995. Coastal marine eutrophication: a definition, social causes, and future concerns. Ophelia 41: 199-219.

Nixon, S. W., 2009. Eutrophication and the macroscope. Hydrobiologia (this issue). doi:10.1007/s10750-009-9759-z.

Nørring, N. P. \& E. Jørgensen, 2009. Eutrophication and agriculture in Denmark: 20 years of experience and prospects for the future. Hydrobiologia (this issue). doi: 10.1007/s10750-009-9772-2.

Olivé, I., M. P. García-Sánchez, F. G. Brun, J. J. Vergara \& J. L. Pérez-Lloréns, 2009. Interactions of light and organic matter under contrasting resource simulated environments: the importance of clonal traits in the seagrass Zostera noltii. Hydrobiologia (this issue). doi:10.1007/ s10750-009-9773-1.

Petersen, J. D., N. Rask, H. B. Madsen, O. T. Jørgensen, S. E. Petersen, S. V. Koch Nielsen, C. B. Pedersen \& M. H. Jensen, 2009. Odense Pilot River Basin: implementation of the EU Water Framework Directive in a shallow eutrophic estuary (Odense Fjord, Denmark) and its upstream catchment. Hydrobiologia (this issue). doi: 10.1007/s10750-009-9774-0.

Savchuk, O. P. \& F. Wulff, 2009. Long-term modeling of large-scale nutrient cycles in the entire Baltic Sea. Hydrobiologia (this issue). doi:10.1007/s10750-009-9775-z.

Savchuk, O. P., T. R. Eremina, A. V. Isaev \& I. A. Neelov, 2009. Response of eutrophication in the eastern Gulf of Finland to nutrient load reduction scenarios. Hydrobiologia (this issue). doi:10.1007/s10750-009-9776-y.

Smith, V., 2006. Responses of estuarine and coastal marine phytoplankton to nitrogen and phosphorus enrichment. Limnology and Oceanography 51: 377-384.

Soetaert, K., \& J. J. Middelburg, 2009. Modeling eutrophication and oligotrophication of shallow-water marine systems: the importance of sediments under stratified and well-mixed conditions. Hydrobiologia (this issue). doi: 10.1007/s10750-009-9777-x.

Vaquer-Sunyer, R. \& C. M. Duarte, 2008. Thresholds of hypoxia for marine biodiversity. Proceedings of the National Academy of Sciences 105: 15452-15457. 